\title{
Organizational Structure, Determinants of Promotion, and Gender Differences in Attainment
}

\author{
Seymour Spilerman
}

Columbia University

and

\section{Trond Petersen}

University of California, Berkeley

\begin{abstract}
In this paper, we differentiate between merit and vacancy driven promotion regimes. In the former, a vacancy at a higher level is not necessary for promotion; in the latter, a job opening is required. Using work histories from a large insurance company we investigate the implications for individual attainment from exposure to each of the advancement systems. We also examine how organizational structures differentially generate the two kinds of advancement regimes. Vacancy-based moves represent discontinuities in an otherwise orderly career progression; they become relevant when an employee reaches the ceiling grade of a job ladder or wishes to change work location. We conclude by examining the ability of this formulation of promotion regimes to account for the lower rates of attainment by women, relative to men, in large corporate settings. @1999 Academic Press
\end{abstract}

In recent years, much attention has been directed to exploring the mediating role of institutional structures in the attainment process. The institutional features that have been examined are of two kinds: labor market structure - arrangements external to the workplace - and the internal organization of the firm. In the case of labor market structure, the analytic units are firms, industries, and sectors; the arrangements pertinent to these units involve entry barriers to employment and transferability of skills; and the issues of interest in attainment research concern the dynamics of movement among firms and the returns-in earnings and status- to particular move patterns. In the case of internal organizational struc-

This research was supported by the National Institute on Aging, grant \#AG04367 to Spilerman. Petersen wishes to acknowledge support from the Institute of Industrial Relations at the University of California, Berkeley.

Address correspondence and reprint requests to Seymour Spilerman, Department of Sociology, Fayerweather Hall \#55, Columbia University, New York, NY 10027. 
ture, the relevant features are job ladders, hierarchical levels, divisions, and departments; the institutional arrangements linking the units are promotion rules, transfer districts, posting and bidding provisions; and the pertinent issues in attainment research concern job changes within the firm, salary returns to particular career paths, and the determinants of employee departures.

Early attempts to extend the status attainment paradigm to incorporate institutional elements concentrated on the implications of labor market structure. Notions of "dual" and "segmented" markets, "core" and "periphery" industries, are but a few of the concepts developed in this literature. In the context of these formulations, researchers have examined the strength of barriers to movement between labor market categories (Althauser and Kalleberg, 1981; Tolbert, 1982; Sorensen and Tuma, 1980; Blossfeld and Mayer, 1988), the tendency for careers in different sectors to have distinctive prospects for status and salary growth (Freedman, 1976; Beck, Horan, and Tolbert, 1978; Carroll and Mayer, 1986; Baron and Bielby, 1984), and reasons for the concentration of minorities and women in particular labor market segments (Rosenfeld, 1983; Daymont, 1980).

Investigation of the structural arrangements internal to a firm, with attendant implications for individual attainment, has been a more recent development. The data for examining this theme are difficult to obtain, as information is necessary on both a firm's organizational structure and the work histories of its employees. Few firms will permit a researcher such extensive access to corporate records. In the rare case where employee histories are made available, a researcher must still contend with the issue of generalizability of the findings, since the particular firm studied can hardly be viewed as a random selection from a specified universe of organizations, nor can its employees be considered a sample from some known population of workers.

Despite these evident limitations, it is now widely recognized that organizational structures and personnel rules have a profound impact on occupational attainment, and that the firm is the preferred analytic site for examining these institutional arrangements (Grandjean, 1981; Baron and Bielby, 1980, 1982; Prendergast, 1996; Bridges and Villemez, 1994; Medoff and Abraham, 1980; DiPrete and Soule, 1986, 1988; Bruderl, Dickmann, and Preisendorfer, 1991). This recognition derives from two considerations: First, a realization that much of an individual's work career is spent within a very few firms and the details of job changes within an organization cannot be adequately studied from a sample representative of an areal labor market, whether city or nation. ${ }^{1}$ Second, a

1 The most severe problem with attempting to assess within-firm mobility from a sample representative of some labor market area is that the occupational coding schemes in wide use, which apply to the full economy (e.g., the 3-digit U.S. Census classification), are insensitive to many within-firm occupation changes. For example, in the 1970 Census classification, the various police ranks (captain, lieutenant, sergeant, detective, patrolman) were denoted by a single code (964). The 1980 and 1990 Census classifications are somewhat improved, in that the five police ranks are now mapped onto two codes $(414,418$ in both years) but much of the occupational differentiation in this line of work is still lost. 
recognition that certain processes, vital to comprehending the course of individual attainment, are well-defined only at the level of the firm. The latter comment is especially relevant to the concept of promotion.

\section{The Measurement of Promotion}

A central motivation for investigating advancement processes stems from the intimate linkage between promotion and occupational achievement. If we conceive of a work career as consisting of a sequence of affiliations with different firms, then during the intervals of continuous employment, the principal means of status growth is through promotion. In this circumstance, one would have expected research studies into the determinants of occupational attainment to have made the analysis of promotion processes a centerpiece of the investigation. Yet, this theme was virtually ignored in the early status attainment literature. ${ }^{2}$

Promotion processes probably received little attention because they are intrinsically difficult to study from an areal population sample - the common sort of data collection in attainment research. One problem is that the very notion of what constitutes a promotion varies by industry, even by firm within an industry. In some workplaces, promotion is identified with a change of occupational title and related duties; in others, it is associated with an increase in "salary grade" - a rank in a nonfunctional status hierarchy-and need not entail a change of responsibilities or job title (Petersen, Spilerman, and Dahl, 1990, p. 334).

Attempts to understand the fine details of promotion regimes are further hampered by the fact that, even within a single definitional specification, the rules which govern advancement can differ considerably among firms (Spilerman, 1986). Some workplaces heavily weigh seniority or duration in rank; others base promotion decisions on performance evaluations or test scores. As a result, with an areal population sample, the analysis of the determinants of promotion is plagued by problems of variant definition and diverse personnel rules. Much of this difficulty can be avoided by examining attainment in a single firm.

\section{Promotion Regimes}

For the purpose of investigating the dynamics of career growth, it is useful to distinguish between two types of promotion regimes. The first is the vacancydriven system. In this system, for a promotion to occur, there must be a job opening at a higher organizational level. Eligible employees then compete for the position and the outcome is determined by considerations of merit, seniority, and the like. Vacancy-driven systems are characterized by a more or less fixed distribution of personnel over occupational titles-often determined by the production technology - and employ a definition of promotion as upward movement in the occupational hierarchy.

From the point of view of personnel management, vacancy-driven regimes are

2 The term "promotion" does not appear in the indexes of major studies of occupational attainment, such as Blau and Duncan (1967), Jencks (1972), or Featherman and Hauser (1978). 
problematic in that an individual's advancement prospects are subject to the "tyranny of demography." Depending on the age distribution of employees, the firm's growth rate, and its rate of employee termination, the number of vacancies will vary from year to year. The problem encountered by management in a vacancy-driven system, therefore, is to motivate and retain key employees in a context in which the coupling between productivity and promotion, the latter a reward for superior performance, is loose.

In merit-driven promotion regimes, the second type, this problem is solved by separating the metric of status rank from occupational task and title. A new structural dimension is created-the grade level hierarchy-onto which all occupational titles are mapped. (Typically, each title ranges over several grades; in the firm we studied, for example, "secretary" spans seven grades.) Promotion is then defined as upward movement in the grade level hierarchy. We have termed this regime "merit-driven" because there is no need for a vacancy in order for promotion to occur-one can be promoted and yet continue with the same job tasks. Basing status (and salary) on grade level effectively decouples promotion decisions from vacancies and permits a tighter association between performance and advancement. The main problem in merit-driven systems is a tendency toward "grade inflation," with too many employees moving into middle and senior grades over time, increasing the salary burden of the organization.

Most contemporary large firms combine these two ideal-type promotion systems. Jobs are distributed into career ladders. A grade range is assigned to each, with the top grade serving as a ceiling to advancement in the career line. Within-ladder promotions depend on merit. Employees can move upward with little consideration of vacancy constraints as long as they meet the minimum performance criteria. Promotion within a ladder means higher salary and more prestige, but not necessarily a change in job duties or job title. Once the ceiling grade is reached, further advancement depends on securing a transfer to another career ladder with a higher ceiling.

A change of ladder, however, entails a shift in work tasks and, possibly, in organizational unit as well. Ladder changes require the availability of a vacancy. Viewed from the perspective of the employee, career moves which depend on a vacancy constitute fissures in an otherwise orderly and fairly predictable advancement progression. When confronted with mobility blockage in a ceiling grade, employees must calculate their options-seek a vacancy in another career line, leave the firm, or stay put in the ceiling grade. Following this formulation, the intent of the present paper is to explore the volume and determinants of these alternative responses to the blockage and examine how they are influenced by organizational features of a firm.

\section{ORGANIZATIONAL STRUCTURE AND PROMOTION PROSPECTS}

Organizational structure, as it is relevant to individual achievement, refers to formal arrangements of personnel in the workplace-departments, divisions, job ladders, etc.-which effectively pattern career opportunity. If organizational 
structure influences attainment, it does so by creating discontinuities in the rate of promotion, so that the corporate unit to which an employee belongs becomes consequential. These discontinuities, in turn, generate particular adaptive behaviors by employees, which can be detected in their patterns of job changing and termination rates.

The structural arrangements that we consider in this paper, in regard to their impact on promotion, are grade level, job focus (line of work), and residence location. The first two are common human resource categories in companies that employ conventional procedures of job evaluation/compensation designvirtually all large corporations (Sibson, 1981; Wallace and Fay, 1983); the third is relevant to understanding attainment in a decentralized firm, such as the one we have investigated. The specific hypotheses which we address are motivated below, in the context of describing the organizational structure of the firm.

The information for this study comes from the employee database of a large insurance company with headquarters in New York City. Our data cover the work histories of new hires during 1971-78, as well as employees of record at year-end 1970. For each worker, in addition to the standard background items, we have details on all jobs held within the company. As a steady-state personnel system, approximately 16,000 individuals were employed at any given time; with the inclusion of entrants and departers, the data file covers some 40,000 work histories.

The insurance company is not unionized. It utilizes a human resource system based on conventional procedures of job evaluation. In particular, all positions below the rank of Assistant Vice President are assigned to one of 20 grade levels; these grades constitute a hierarchy of overlapping salary ranges. ${ }^{3}$ At times of performance evaluation, carried out twice a year for each employee, a manager has the discretion to increase a subordinate's salary - but only within the range associated with his grade. A move to a higher grade constitutes a promotion and requires the approval of an assistant vice-president. An essential feature of this system is that promotion can be allotted as a reward for superior performance or long tenure, without an accompanying change in a worker's duties and without the presence of a vacancy.

The company does not record detailed job titles (which are formulated by a manager for his subordinates) but classifies an employee according to one of 40 "job foci," which are line-of-work or job ladder-type structures. In practice, it is the job foci (rather than detailed job titles) which are slotted into the grade level distribution, a sequence of salary grades being assigned to each focus. Careers, then, can be tracked in the employee database in terms of changes in job focus and grade level.

Some foci clearly are occupational lines (e.g., programmer, typist, secretary); others are vague in terms of job tasks, conveying broad areas of responsibility

${ }^{3}$ For example, in 1978 , the salary range in grade 5 was $\$ 9229$ to $\$ 13,387$, in grade 6 it was $\$ 10,076$ to $\$ 15,120$, and in grade 7 it was $\$ 11,236$ to $\$ 16,854$. 
TABLE 1

Distribution of Employees in the Insurance Company by Salary Grade Level and Job Focus Category, $1977^{a}$

\begin{tabular}{|c|c|c|c|c|c|c|c|c|c|c|c|}
\hline \multirow{4}{*}{$\begin{array}{l}\text { Salary } \\
\text { grade }\end{array}$} & \multicolumn{11}{|c|}{ Job focus } \\
\hline & (1) & (2) & & (4) & (5) & (6) & (7) & (8) & (9) & (10) & (11) \\
\hline & Machine & Secretary/ & (3) & Figure & Misc. & Claims/ & Math/ & Sales & Underwrtng/ & "Focus & Misc. \\
\hline & Operator & Steno & Typist & Clerk & Clerical & Contract & Program. & Support & Investment & $50 " b$ & Administ. \\
\hline 1 & 11 & 141 & 113 & & 202 & & & & & & \\
\hline 2 & 139 & 256 & 212 & 108 & 426 & & & & & & \\
\hline 3 & 245 & 491 & 295 & 353 & 434 & & & & & & \\
\hline 4 & 131 & 555 & 214 & 109 & 642 & 264 & & & & & \\
\hline 5 & 99 & 412 & 123 & 70 & 572 & 77 & & & & 196 & 29 \\
\hline 6 & 32 & 301 & 12 & 11 & 163 & 184 & 76 & 115 & 88 & 129 & 223 \\
\hline 7 & 32 & 114 & & & 23 & 99 & 73 & 139 & 112 & 153 & 201 \\
\hline 8 & 27 & & & & 17 & 61 & 75 & 100 & 85 & 144 & 155 \\
\hline 9 & 48 & & & & & 52 & 113 & 67 & 42 & 160 & 100 \\
\hline 10 & & & & & & 47 & 103 & 46 & 102 & 216 & 126 \\
\hline 11 & & & & & & 18 & 78 & 33 & 82 & 189 & 52 \\
\hline 12 & & & & & & & 71 & 76 & 92 & 227 & 85 \\
\hline 13 & & & & & & & & & & 324 & \\
\hline 14 & & & & & & & & & & 368 & \\
\hline 15 & & & & & & & & & & 267 & \\
\hline 16 & & & & & & & & & & 271 & \\
\hline 17 & & & & & & & & & & 188 & \\
\hline 18 & & & & & & & & & & 154 & \\
\hline 19 & & & & & & & & & & 100 & \\
\hline 20 & & & & & & & & & & 69 & \\
\hline
\end{tabular}

${ }^{a}$ Entries are number of employees on January 1, 1977. For readability, a few scattered entries with $n<9$ have been suppressed. Foci (1)-(5) are classified by the company as "clerical," foci (6)-(11) are termed "administrative."

${ }^{b}$ Substantive job focus is not assigned. See text for details.

(e.g., claims analysis, corporate relations). To clarify this scheme, we present in Table 1 the distribution of employees by 11 aggregates of the 40 foci and by grade level. The first five foci are clerical lines; the remainder are administrative and professional categories. Focus 50 (category 10) is a heterogeneous code devised by the company; it covers "exempt jobs" (not eligible for overtime) in all work lines, as well as employees in salary grades higher than $12 .{ }^{4}$

\section{Ceiling Grades}

What is evident from this table are the very different grade distributions of the job foci and the fact that, while each provides an opportunity for several promotions without having to change line of work, a number have low ceiling grades which may function to impede advancement. Through its "posting and bidding" provisions, ${ }^{5}$ the company seeks to facilitate lateral transfers, and many

${ }^{4}$ Job focus is assigned by the insurance company only through grade 12 . All employees in higher grades are classified as "focus 50." In our data, there were 108 instances of individuals in grades 13 and higher having an assigned focus code other than code 50 . These errors reflect laxity in updating the focus variable once it is no longer applicable. In Table 1, these entries have been recoded as focus 50 .

5 Before job vacancies can be filled with outside hires, they must be advertised internally, giving current employees a first opportunity to apply. 
workers certainly avail themselves of the possibility of moving to a focus with a higher ceiling. At the same time, such shifts can require a change of work group or even residence location; faced with the prospect of severe dislocation, some employees surely choose to forego further mobility. As our first hypothesis, then, following DiPrete and Soule (1988), we suggest that the ceiling grades of the job foci serve as structural barriers to advancement, lowering the promotion rate in the associated ranks.

The next two hypotheses refer to employee responses to the promotion blockage. If advancement prospects are depressed in the ceiling grades, this does not mean that motivated individuals are devoid of options. They could terminate employment, choosing to pursue occupational advancement elsewhere (hypothesis 2). Alternatively, if the posting and bidding provisions effectively permit career line transfers, as management contends, the pattern of focus shifts should reveal this situation. In particular, as a ceiling grade is approached, we should note an increased tendency to move to other foci, especially to ones with higher ceiling barriers (hypothesis 3).

The magnitude of each of these personnel flows will depend on the demand for focus changes and the availability of job slots, as well as on the effectiveness of the posting and bidding provisions as a matching mechanism. It is likely that some companies, with liberal transfer rules, will experience few employment terminations because the volume of vacancies in alternate career lines is sufficient to accommodate all workers who wish to change. In other firms, in contrast, the same transfer provisions might be accompanied by a high termination rate because few vacancies are available in potential destination foci. All that can be said is that the two behavioral responses-departure and lateral shift—represent alternative adaptations to the mobility blockage; the size of the respective flows will reflect the availability of suitable jobs, within the company and in other firms in the labor market area.

\section{Residence Location}

Large corporations frequently have a decentralized organizational structure, with plants or agencies in several communities. A major insurance company, of necessity, has such an institutional configuration because the nature of its business requires frequent contact with customers who are scattered through the country. In the case of the firm we have studied, some $48 \%$ of the employees work at the corporate headquarters in New York City. The remaining staff are dispersed, assigned to regional and local offices in the 50 states.

We expect the impact of the ceiling grades to be pronounced for employees who reside outside the headquarters city. For an individual in a local office, a shift to a job opening in a different line of work may require relocating to another community, raising the social cost of a residence change. The necessity of a geographic move would be less critical for the home office staff. With approximately 8000 jobs in a single location, one can expect numerous vacancies each year in suitable destination foci. For our fourth proposition, we therefore suggest 
the possibility of an interaction between location and ceiling grade, with the promotion blockage being less severe for home office employees.

\section{Implications for Women's Careers}

The distinction between merit and vacancy-driven promotion regimes may have particular import for the careers of women. Women comprise $89 \%$ of clerical workers in the insurance company, versus $43 \%$ of employees in the administrative lines. In terms of salary grade, they constitute $91 \%$ of workers in grades $1-3,82 \%$ in grades $4-7$, but only $11 \%$ in grades 15 and above. Therefore, consistent with the reports of others (e.g., Bielby and Baron, 1984; DiPrete and Soule, 1988), women in this firm are concentrated in the clerical foci and in low organizational ranks-precisely the positions most vulnerable to the ceiling grade constraints.

Residence location is also likely to be consequential for women's career progress. When occupational advancement requires relocating to a different community to take advantage of a vacancy, this can be problematic for a married women as it necessitates a complementary shift in husband's place of employment. There is much evidence that when the career needs of spouses come into conflict, it is the husband's work career which is accorded primacy by the couple (Marwell, Rosenfeld, and Spilerman, 1979; Hoffman and Reed, 1981; Spilerman and Schrank, 1991). For this reason, we examine the differential impact of position in the firm and office location on the advancement prospects of men and women.

\section{THE ANALYTIC FORMULATION: IMAGERY AND METHOD}

We view the human resource system of the insurance company as a collection of personnel flows among the 20 grade levels. Individuals can be hired into any rank (during the 1970's, $86 \%$ of new employees entered in grades 1-4). From the point of entry, with the passage of time, workers are at risk of two kinds of events-promotion to a higher grade and departure from the company. Salary grades are emphasized in this formulation because the grade hierarchy is explicit is written documents, is clearly perceived by the employees, and because promotion is defined in terms of movement in this hierarchy.

Following the company's personnel rules, we define promotion as an increase in grade level. To allow for the occasional case of a skip in grade, we operationalize promotion as an increase of one to three ranks. In our analysis of advancement, all other endings to the stay in a grade - whether departure from the company, end of data collection, or the rare case of demotion-are treated as censored observations. Similarly, in our analysis of departures, all endings to the duration in a grade, aside from employment termination, are treated as censored observations.

The methodology that corresponds to this formulation draws from the regression methods of survival analysis (Kalbfleisch and Prentice, 1980; Tuma, Hannan, and Groeneveld, 1979; Miller, 1981). Our investigation into the determinants of 
promotion from grade $\mathrm{i}(\mathrm{i}=1,20)$ is based on spells in grade $\mathrm{i}$ by all employees who were in this rank sometime during 1971-1978. The results we report are based on 33,468 spells - covering 16,146 workers; this represents a 50\% random sample of individuals employed by the insurance company during the 8 -year interval.

We specify a continuous-time transition rate model. With respect to advancement, let the rate of promotion from salary grade $\mathrm{i}$, after duration $\mathrm{t}$ in the grade, be

$$
\mathrm{h}_{\mathrm{i}, \mathrm{i}+1}[\mathrm{t} \mid \mathbf{x}(\mathrm{t})]=\lim _{\Delta \mathrm{t} \downarrow 0} \mathrm{P}_{\mathrm{i}}[\mathrm{t} \leq \mathrm{T}<\mathrm{t}+\Delta \mathrm{t} \mid \mathrm{T} \geq \mathrm{t} ; \mathbf{x}(\mathrm{t})] / \Delta \mathrm{t}
$$

where $\mathrm{T}$ is a random variable denoting months in grade $\mathrm{i}$ (the model "clock"), $\mathbf{x}(\mathbf{t})$ is a vector of covariates that influence the promotion rate, and $\mathrm{P}[\cdot]$ denotes a probability. The shape of the hazard, $\mathrm{h}_{\mathrm{i}, \mathrm{i}+1}[\mathrm{t} \mid \mathbf{x}(\mathbf{t})]$, is not a topic that is addressed in this paper (though there is some basis for postulating a unimodal function ${ }^{6}$ ). To avoid biases in the covariates which could result from imposing an incorrect functional form, we adopt a specification in which the baseline hazard is free to vary.

The particular hazard model used in this study is the following:

$$
\mathrm{h}_{\mathrm{i}, \mathrm{i}+1}[\mathrm{t} \mid \mathbf{x}(\mathbf{t})]=\Sigma\left(\lambda_{\mathrm{p}} \tau_{\mathrm{p}}\right) \exp \left[\mathbf{b}^{\prime} / \mathbf{x}(\mathbf{t})\right]
$$

where $\tau_{\mathrm{p}}$ is a dummy variable that refers to time in grade $\mathrm{i}$ (coded one for $\mathrm{t}$ in the interval $\left[\mathrm{t}_{\mathrm{p}}, \mathrm{t}_{\mathrm{p}+1}\right), \mathrm{t}_{\mathrm{p}}=0,3,5,7,13,25,61$ months, and zero otherwise), $\lambda_{\mathrm{p}}$ is a constant that conveys the base rate in the interval, and $\left\{\lambda_{\mathrm{p}}\right\}$ describes a step function approximation to the baseline hazard. The vector $\mathbf{b}$ in this formulation conveys the effects of the covariates. These consist of two groupings of terms: (a) human capital variables and other background characteristics (education, age, sex, race, seniority) and (b) the several facets of organizational structure that were described in the preceding section (grade level, office location, and job focus; the last summarized by a dummy variable that distinguishes between the clerical and administrative job lines).

The same step function formulation (equation 2) was used to model the departure rate from the firm. Variables such as age and seniority are known to have negative effects on the likelihood of termination (see, e.g., Pettman, 1973, p. 53; Mobley, 1982, pp. 96-97) and are introduced here as covariates. However, to maintain the competing risk imagery, we again use time-in-grade as the system clock.

6 The argument for a unimodal hazard function is the following: At entrance into grade i, the probability of an immediate promotion is low. With increasing duration, an individual's promotion prospects rise to a peak (at a time characteristic of the grade), then decline if the employee continues to be passed over. Kanter (1977, pp. 129-139), Van Maanen (1977, p. 35), and Sofer (1970, pp. 234-252; 270-275) write of company norms for duration in a grade, which, by implication, would generate a unimodal hazard. 


\section{THE CONSEQUENCES OF ORGANIZATIONAL STRUCTURE}

\section{Ceiling Grade Effects}

The data reported in Table 1 suggest clear limits to the attainable salary grades in many of the job foci. For the administrative lines (foci 6-11), the appearance of blockage is largely illusory, since job focus is assigned by the company only through grade 12. As noted earlier, all employees in higher ranks are classified as "focus 50" (see footnote 4). Thus, for administrative employees, there are few true ceiling grades that are discernible in the data.

For the clerical foci, in contrast, the ceiling grades are not an artifact of the personnel assignment scheme. In some instances, there is an abrupt termination to the possibility of advancement in a career line (e.g., focus 2); more commonly, there is a gradual fall-off, over several ranks, in the number of employees. In general, the contraction in advancement opportunity occurs over grades 4-7. For this reason, and because the blockage may spill over from a ceiling grade to the preceding rungs in a job ladder, we postulate reduced promotion rates in this range of grades, rather than explore detailed focus $\times$ grade interactions.

In Table 2, we present three regression models, of the form described by equation (2), that are designed to assess the impact of the foci ceilings on the rate of promotion. In column (1), zero-order effects of the different salary grades are reported, relative to grades 1-3. Aside from the fall-off in grades 15-20, the promotion rate is lowest in grades $4-5$ and $6-7$, precisely the ranks in which the foci ceilings are concentrated.

In column (2), controls have been added for some standard background items: race, sex, education, age, and seniority. The effects of these variables are in line with our expectations. The promotion rate is low for blacks and Hispanics (relative to whites) and for women. It increases with education, but declines with seniority and age; the positive squared terms reveal a slowing in the rate of decline with age and tenure. The fact that there are no surprises in these results (see, e.g., Sandefur, 1981; Rosenbaum, 1984, pp. 75-83; and Medoff and Abraham, 1981, pp. 208-209, for similar assessments) bolsters our confidence in the conventionality of the firm's personnel procedures and in the consequent generalizability of our findings to other corporate bureaucracies.

Net of the controls, there remains an evident detrimental effect on advancement prospects from location in salary grades 4-5 and 6-7. Exponentiating the regression coefficients (not shown), we find that, whereas the promotion rates do not differ materially between grades $1-3$ and $8-20$, in SGL's $4-5$ and 6-7, they are, respectively, 80 and $89 \%$ of the base figure. The depressed rate in the highest salary grades, noted in relation to column (1), is now much reduced in magnitude. The earlier, negative value appears to reflect a fall-off in the promotion rate by older employees approaching retirement age, who are overrepresented in the top ranks of the company. With age and seniority held constant, it is apparent that promotion prospects are fairly uniform over the grade range, except for the ranks which contain the foci ceilings. 
TABLE 2

Effects of Organizational Characteristics and Individual Background Variables on the Promotion Rate ${ }^{a}$

Model

Variable $^{b}$

(1)

(2)

\begin{tabular}{|c|c|c|c|}
\hline \multicolumn{2}{|l|}{ Black } & $-.096^{*}$ & $-.098^{*}$ \\
\hline \multicolumn{2}{|l|}{ Oriental } & .046 & .044 \\
\hline \multicolumn{2}{|l|}{ Hispanic } & $-.101 *$ & $-.097 *$ \\
\hline \multicolumn{2}{|l|}{ Female } & $-.104 *$ & $-.094 *$ \\
\hline \multicolumn{2}{|l|}{ Education (years) } & $.061 *$ & $.054^{*}$ \\
\hline \multicolumn{2}{|l|}{ Age (years) } & $-.044^{*}$ & $-.045^{*}$ \\
\hline \multicolumn{2}{|l|}{$\mathrm{Age}^{2}$} & $.00025 *$ & $.00027 *$ \\
\hline \multicolumn{2}{|l|}{ Seniority (mos.) } & $-.0030^{*}$ & $-.0030^{*}$ \\
\hline \multicolumn{2}{|l|}{ Seniority $^{2}$} & $.0000040 *$ & $.0000038 *$ \\
\hline SGL4-5 & $-.380 *$ & $-.223^{*}$ & .059 \\
\hline SGL6-7 & $-.350^{*}$ & $-.109^{*}$ & .010 \\
\hline SGL8-10 & $-.161^{*}$ & $.081 * *$ & $.106^{*}$ \\
\hline SGL11-14 & $-.208^{*}$ & $.091 * *$ & $.126^{*}$ \\
\hline SGL15-20 & $-.375^{*}$ & -.016 & .027 \\
\hline Cleric $\times$ SGL4-5 & & & $-.306^{*}$ \\
\hline Cleric $\times$ SGL6-7 & & & $-.395^{*}$ \\
\hline$\chi^{2}$ & 4,114 & 6,337 & 6,428 \\
\hline$N$ (spells) & 33,468 & 33,468 & 33,468 \\
\hline Pct. completed & .510 & .510 & .510 \\
\hline
\end{tabular}

a Entries are unstandardized regression coefficients from a survival model. Each equation also contains seven dummy terms which convey the effect of duration in grade (see text equation 2). In this formulation, the constant term in the covariate vector is not identified and is absorbed into the duration terms.

$b$ "White" is the omitted category among the racial terms; "SGL1-3" is the omitted category among the grade level terms. "Cleric" is a dummy variable, coded one for job foci $1-5$ and zero otherwise. Interactions with SGL dummies were estimated only for grades having both clerical and administrative employees. See footnote 7 regarding omission of the clerical main effect.

$* p<.01, * * p<.05$.

Can we be certain that the depressed rates of advancement in grades 4-5 and 6-7 reflect the impact of the foci ceilings and not a company policy to maintain a lower promotion rate in certain ranks? This question is explored in column (3), where interaction terms have been added to detect the possibility of different promotion rates in the administrative and clerical lines. ${ }^{7}$ If our argument about the ceiling effects is correct, the fall-off in grades 4-5 and 6-7 should occur only in the clerical foci, where the blockage exists, and not in the administrative lines.

The results in column (3) lend credence to this contention. The added terms for

7 A main effect term for "clerical focus" was not included because we wish to contrast the promotion rates of clerical and administrative workers in the same grades, rather than compute an average tendency for each of the focus categories. The grade paths in promotion rates for clerical and administrative workers are most clearly seen in Fig. 1. 


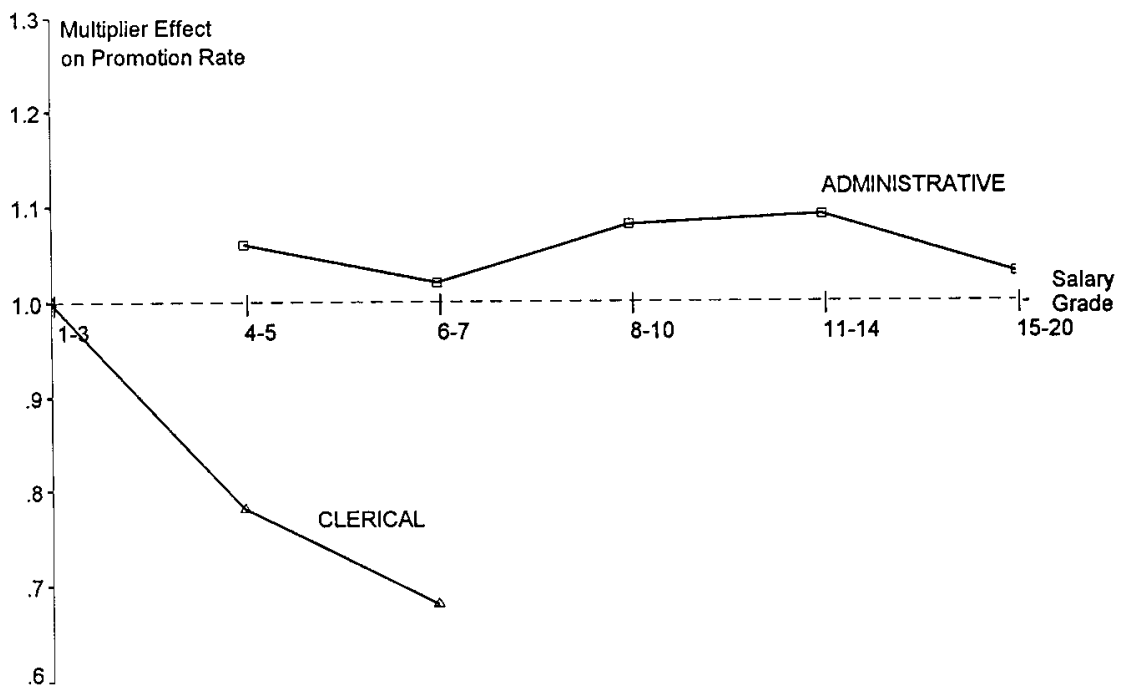

FIG. 1. Grade level effects on the promotion rate, for clerical and administrative foci. Data are from model (3) of Table 2. Each entry conveys the multiplier effect (parameter antilog) on the promotion rate in the indicated job focus/SGL category, relative to SGL1-3. Very few clerical employees are in ranks higher than salary grade 7; no employee in an administrative focus is in a grade lower than 4 (see Table 1).

interactions with the clerical focus are negative and substantial. Moreover, when the effects are calculated separately for the administrative and clerical lines (Fig. 1 ), it becomes clear that, whereas there is little variation in the promotion rate of the former, in the clerical ladders, the fall-off in the ceiling grades is considerable. Hypothesis 1 of this paper, which postulated that the foci ceilings are a structural impediment to advancement, is therefore confirmed.

\section{Patterns of Focus Changing}

How do workers adjust to the impending approach of a ceiling grade? In particular, what can be said about the effectiveness of the posting and bidding provisions, arrangements widely used in American industry ${ }^{8}$ and instituted, in part, to permit qualified, motivated workers to circumvent the ceiling blockage and continue their upward mobility? In Table 3, we examine the pattern of job focus changing by clerical employees. To conserve space, we present results for three of the five clerical foci; similar findings characterize the two not shown. Each panel reports the focus affiliation in January, $1979\left(\mathrm{t}_{1}\right)$, of workers who, two years earlier $\left(\mathrm{t}_{0}\right)$, were in the indicated origin focus and grade level.

In Table 3, panel A, we show the destination foci of typists at $\mathrm{t}_{0}$. Examining the

${ }^{8}$ In a survey of 1201 collective bargaining agreements (U.S. Department of Labor 1970, pp. 12-16, 42 ), $52 \%$ were found to utilize posting and bidding provisions in promotion decisions, $63 \%$ in transfer decisions. 
TABLE 3

Patterns of Focus Changing for Clerical Job Lines, by Grade Level, 1977-1979 ${ }^{a}$

A. 3-Typist at $t_{0}$

\begin{tabular}{|c|c|c|c|c|c|c|}
\hline \multirow{2}{*}{$\begin{array}{l}\text { Grade } \\
\text { level } \\
\text { at } t_{0}\end{array}$} & \multicolumn{5}{|c|}{ Job focus at $t_{1}\left(\right.$ percent $\left.^{b}\right)$} & \multirow[b]{2}{*}{$\begin{array}{c}N \\
\text { (at } t_{0} \text { ) }\end{array}$} \\
\hline & Same & $\begin{array}{c}\text { 2-Sec'y/ } \\
\text { Steno }\end{array}$ & $\begin{array}{c}\text { 4-Figure } \\
\text { Clerk }\end{array}$ & $\begin{array}{l}\text { 5-Misc. } \\
\text { Clerical }\end{array}$ & $\begin{array}{c}\text { 6-Claims/ } \\
\text { Contract }\end{array}$ & \\
\hline 1 & 45 & 6 & 13 & 11 & 0 & 47 \\
\hline 2 & 42 & 8 & 6 & 33 & 2 & 104 \\
\hline 3 & 36 & 14 & 4 & 34 & 3 & 179 \\
\hline 4 & 28 & 12 & 2 & 32 & 9 & 154 \\
\hline 5 & 18 & 11 & 1 & 23 & 22 & 94 \\
\hline
\end{tabular}

B. 5-Miscellaneous Clerical at $t_{0}$

\begin{tabular}{ccccccr} 
Grade & \multicolumn{5}{c}{ Job focus at $t_{1}\left(\right.$ percent $\left.^{b}\right)$} & \\
\cline { 2 - 6 } $\begin{array}{l}\text { level } \\
\text { at } t_{0}\end{array}$ & Same & $\begin{array}{l}\text { 1-Machine } \\
\text { Operator }\end{array}$ & $\begin{array}{l}\text { 4-Figure } \\
\text { Clerk }\end{array}$ & $\begin{array}{l}\text { 6-Claims/ } \\
\text { Contract }\end{array}$ & $\begin{array}{c}\text { 11-Misc. } \\
\text { Admin. }\end{array}$ & $\begin{array}{c}N \\
\left.\text { (at } t_{0}\right)\end{array}$ \\
\hline 1 & 60 & 23 & 12 & 0 & 0 & 95 \\
2 & 74 & 11 & 4 & 1 & 1 & 254 \\
3 & 76 & 5 & 5 & 2 & 3 & 301 \\
4 & 67 & 2 & 2 & 6 & 11 & 490 \\
5 & 43 & 3 & 1 & 11 & 20 & 447 \\
6 & 21 & 0 & 0 & 27 & 26 & 131
\end{tabular}

C. 2-Secretary/Steno at $t_{0}$

\begin{tabular}{|c|c|c|c|c|c|}
\hline \multirow{2}{*}{$\begin{array}{c}\text { Grade } \\
\text { level } \\
\text { at } t_{0}\end{array}$} & \multicolumn{4}{|c|}{ Job focus at $t_{1}\left(\right.$ percent $\left.^{b}\right)$} & \multirow[b]{2}{*}{$\begin{array}{c}N \\
\text { (at } t_{0} \text { ) }\end{array}$} \\
\hline & Same & $\begin{array}{l}\text { 5-Misc. } \\
\text { Clerical }\end{array}$ & $\begin{array}{l}\text { 8-Sales } \\
\text { Support }\end{array}$ & $\begin{array}{l}\text { 11-Misc. } \\
\text { Admin. }\end{array}$ & \\
\hline 1 & 87 & 11 & 0 & 0 & 73 \\
\hline 2 & 86 & 11 & 0 & 1 & 136 \\
\hline 3 & 88 & 8 & 1 & 1 & 291 \\
\hline 4 & 85 & 8 & 1 & 1 & 359 \\
\hline 5 & 78 & 6 & 4 & 4 & 314 \\
\hline 6 & 74 & 1 & 9 & 6 & 248 \\
\hline 7 & 70 & 1 & 15 & 7 & 97 \\
\hline
\end{tabular}

${ }^{a} t_{0}=$ January $1,1977, t_{1}=$ January 1,1979 . Entries are proportions, and report the focus affiliation of employees at $t_{1}$ who were in the noted origin focus and grade level at $t_{0}$.

${ }^{b}$ Row sums are less than 100 because only the principal destination foci at $t_{1}$ are shown.

first column ("same focus"), it is evident that as the grade level increases and the ceiling is approached, the proportion of employees continuing in the occupational line declines rapidly. By grade 5 , only $18 \%$ of employees who were typists at $\mathrm{t}_{0}$, and have remained with the company through $\mathrm{t}_{1}$, continue in the job focus. Even more significant is the pattern of job changing as the ceiling is neared. In the lowest grade, the bulk of job changing is to figure clerk, a focus with a low ceiling 
(see Table 1). Whatever the reasons for choosing this destination, they do not include a concern with extending one's mobility prospects, and this focus quickly loses favor as the ceiling grade is approached. In contrast, claims/contract, which does extend the attainment horizons of typists, becomes a preferred destination. Less pronounced patterns can be noted for secretary/steno and miscellaneous clerical worker as destination foci; each extends the attainment possibilities of typists, but only by a couple of grades.

The pattern for miscellaneous clerical worker (Panel B), as an origin focus at $\mathrm{t}_{0}$, approximates that of typists. Again, figure clerk is a principal destination in the lowest ranks, where considerations of mobility ceilings do not weigh heavily. With increasing rank, as before, there is an abrupt shift in preferred destination-in this instance, to claims/contract and miscellaneous administrative worker; both are job lines which permit additional advancement. ${ }^{9}$ Finally, an analogous pattern characterizes secretary/steno as an origin job line (Panel C), though there is some difference in choice of destination foci. In low grades, miscellaneous clerical is the principal terminus. As the ceiling is approached, the preferred destination shifts to sales support and miscellaneous administrative, foci which extend the mobility horizons of secretary/steno workers. ${ }^{10}$

\section{Departures}

To this point, we have indicated that, while the rate of advancement is depressed in the ceiling grades, the company's transfer provisions-which are common in American industry-permit many employees to escape the mobility blockage by moving to a focus with a higher grade barrier. In short, the ceilings are permeable, and workers can maneuver to avoid the blockage. This is the essence of our contention in hypothesis 3 . What remains to be determined is the extent to which the foci ceilings also stimulate departures from the company. Termination represents an alternate response to the promotion blockage and the separation rate provides a measure of the adequacy of the transfer provisions in accommodating the career aspirations of middle-level employees.

This issue is addressed in Table 4. In column (1), we report termination rates from the different grade-level categories, net of controls for race, sex, measures of human capital, and office location, the last a dummy term that differentiates

\footnotetext{
9 Machine operator, as a destination focus, does not appear to conform to this pattern. From Table 1, it can be observed that this category has a high ceiling, yet transitions to machine operator take place mainly from the low grades of miscellaneous clerical. This anomaly is due to the heterogeneous nature of the machine operator category. Grouped together are detailed foci such as keypunch operator, which has a low ceiling and to which miscellaneous clerical workers do transfer, and computer operator, which has a high ceiling but requires specialized training and is not a destination for miscellaneous clerical workers.

10 The results for secretary/steno differ from typist and from miscellaneous clerical in both the higher retention rate of the first and in choice of destination jobs. The difference arises from the concentration of secretary/steno workers in local offices, where job change possibilities are limited but where sales support activities are concentrated.
} 
TABLE 4

Ceiling Grade and Location Effects on Rate of Employment Termination ${ }^{a}$

\begin{tabular}{lccc}
\hline & & Model & \\
\cline { 2 - 4 } \multicolumn{1}{c}{ Variable $^{b}$} & $(1)$ & $(2)$ & $(3)$ \\
\hline Black & .018 & .018 & .026 \\
Oriental & -.021 & -.022 & -.013 \\
Hispanic & $-.147^{*}$ & $-.147^{*}$ & $-.140^{*}$ \\
Female & .018 & .015 & $.163^{*}$ \\
Education (years) & $.035^{*}$ & $.036^{*}$ & $.035^{*}$ \\
Age (years) & $-.077^{*}$ & $-.077^{*}$ & $-.079^{*}$ \\
Age & $.00099^{*}$ & $.00099^{*}$ & $.0010^{*}$ \\
Seniority (mos.) & $-.018^{*}$ & $-.018^{*}$ & $-.018^{*}$ \\
Seniority & $.000037^{*}$ & $.000037^{*}$ & $.000037^{*}$ \\
SGL4-5 & $-.280^{*}$ & $-.331^{*}$ & $-.275^{*}$ \\
SGL6-7 & $-.500^{*}$ & $-.537^{*}$ & $-.487^{*}$ \\
SGL8-10 & $-.659^{*}$ & $-.665^{*}$ & $-.634^{*}$ \\
SGL11-14 & $-.918^{*}$ & $-.927^{*}$ & $-.891^{*}$ \\
SGL15-20 & $-1.075^{*}$ & $-1.085^{*}$ & $-1.046^{*}$ \\
Home Office & $-.382^{*}$ & $-.383^{*}$ & $-.183^{*}$ \\
Home Off. $\times$ Female & & & $-.249^{*}$ \\
Cleric $\times$ SGL4-5 & & .056 & \\
Cleric $\times$ SGL6-7 & 9,372 & .121 & 9,392 \\
$\chi^{2}$ & 33,468 & 9,375 & .314 \\
$N$ (spells) & .314 & .314 & \\
Pct. completed & & & \\
\hline
\end{tabular}

${ }^{a}$ Entries are unstandardized regression coefficients from a survival model. Each equation also contains seven dummy terms which depict the effect of duration in grade (see text equation 2). In this formulation, the constant term in the covariate vector is not identified and is absorbed into the duration terms.

$b$ "White" is the omitted category among the racial terms; "SGL1-3" is the omitted category among the grade level terms. "Cleric" is a dummy variable, coded one for job foci 1-5 and zero otherwise. Interactions with SGL dummies were estimated only for grades having both clerical and administrative employees. See footnote 7 regarding omission of the clerical main effect.

$* p=.01, * * p=.05$.

between home office and employment in some other locale (and is discussed in the next section). Note, first, that the human capital variables have their expected effects. Older and more senior workers are less likely to terminate (at decreasing rates); more educated workers, in contrast, have higher turnover rates. ${ }^{11}$ In regard to grade level, there is an almost linear decline with increasing rank; in short, there

11 Age and seniority effects on the termination rate are well established (see, e.g., Sicherman and Galor, 1990). They are explained in terms of the accumulation of firm specific skills, of entitlements that are linked to seniority, and the decline (with age) in years remaining in the labor force, during which one might recoup a lost investment due to a change of employer. The positive effect of education on the likelihood of departure is more difficult to explain (see Sicherman, 1990, for a discussion). Flinn and Heckman (1983) describe conditions under which a positive relationship will hold. 
is no indication of a higher departure rate in grades $4-5$ or $6-7$, as a response to the mobility blockage.

A more sensitive test can be made by comparing the departure rates of clerical and administrative employees in grades $4-5$ and 6-7. Since the ceiling barriers pertain only to the clerical lines, a higher departure rate in these foci would constitute evidence that the transfer provisions of the company are not able to accommodate the career aspirations of many employees who face the structural blockage (hypothesis 2). The results in column (2), however, belie this contention. While the departure rate is higher in the ceiling grades of the clerical lines, the effects are not statistically significant.

In summary, the consequences of the foci ceilings for attainment prospects are the following: They do constitute a substantial blockage in the rate of promotion; the results in Table 2 and Fig. 1 are clear on this point. Yet, the company's transfer provisions appear to effectively facilitate movement between career lines, and this institutional option is used by many clerical employees in order to evade the ceiling barriers (Table 3). As a result, in this company, there is little evidence that the structural blockage stimulates an outflow of personnel, in response to the constraints on mobility.

The depressed promotion rates in the ceiling grades, incidentally, appear to arise from two processes: (a) a slowdown in the advancement of employees who choose to negotiate a career line change, since the mechanics of this move often require a prior investment of time in acquiring new job skills and locating a suitable vacancy, and (b) a decision by some workers to accept the halt in their mobility and not compete for an opening elsewhere in the company. The latter situation is not necessarily perceived as unsatisfactory. There are employees who do not want additional job responsibilities and decline to seek promotion (Hoffman and Reed, 1981). Moreover, the salaries in the senior clerical grades are fairly attractive; for example, in 1978, the maximum earnings in grade 6 were more than twice the starting wage in grade 2.

\section{Location Effects}

So far, the argument we have developed is that the clerical ceilings depress occupational mobility because of the necessity of negotiating a career line change to avoid the promotion blockage. We now suggest that the ceiling grades may be more detrimental to the careers of individuals employed outside the home office (hypothesis 4). In small workplaces, there would be few job openings in a given year in appropriate destination foci, so a decision to change focus might require a move to a new community as well. The possibility that the ceiling grades have a differential impact on occupational advancement, according to residence location, is examined in Table 5.

The equation in column (1) repeats our basic model of the determinants of promotion, with dummy terms added for home office and clerical focus. The contribution of home office is substantial; on average, the promotion rate for employees in the headquarters is $18 \%$ higher (exp[.163] - 1) than in other cities. 
TABLE 5

Effects of Residence Location, Ceiling Grade, and Gender on the Rate of Promotion ${ }^{a}$

\begin{tabular}{|c|c|c|c|c|}
\hline \multirow[b]{2}{*}{ Variable $^{c}$} & \multicolumn{4}{|c|}{ Model } \\
\hline & (1) & (2) & $(3)^{b}$ & (4) \\
\hline Black & $-.137 *$ & $-.143^{*}$ & $-.138^{*}$ & $-.148 *$ \\
\hline Oriental & .029 & .030 & .121 & .026 \\
\hline Hispanic & $-.136^{*}$ & $-.142 *$ & $-.145^{*}$ & $-.146^{*}$ \\
\hline Female & $-.081 *$ & $-.075^{*}$ & $-.134 *$ & $-.189 *$ \\
\hline Education (years) & $.057 *$ & $.058 *$ & $.053^{*}$ & $.057^{*}$ \\
\hline Age (years) & $-.035^{*}$ & $-.033^{*}$ & $-.027^{*}$ & $-.032 *$ \\
\hline $\mathrm{Age}^{2}$ & .00014 & .00011 & .000064 & -.000093 \\
\hline Seniority (mos.) & $-.0031^{*}$ & $-.0031^{*}$ & $-.0049 *$ & $-.0032 *$ \\
\hline Seniority $^{2}$ & $.0000041^{*}$ & $.0000042 *$ & $.0000085^{*}$ & $.0000043^{*}$ \\
\hline SGL4-5 & $-.273^{*}$ & $-.279^{*}$ & $-.291^{*}$ & $-.279 *$ \\
\hline SGL6-7 & $-.438^{*}$ & $-.444^{*}$ & $-.498^{*}$ & $-.454^{*}$ \\
\hline SGL8-10 & $-.323 *$ & $-.325^{*}$ & $-.425^{*}$ & $-.349 *$ \\
\hline SGL11-14 & $-.328^{*}$ & $-.331^{*}$ & & $-.359^{*}$ \\
\hline SGL15-20 & $-.433^{*}$ & $-.435^{*}$ & & $-.460 *$ \\
\hline Clerical & $-.380 *$ & $-.421 *$ & & $-.379 *$ \\
\hline Home Office & $.163 *$ & $.123^{*}$ & $.168 *$ & $.060 * *$ \\
\hline $\mathrm{HO} \times$ Clerical & & $.071 * *$ & & \\
\hline $\mathrm{HO} \times \mathrm{SGL} 4-7$ & & & $.112 *$ & \\
\hline $\mathrm{HO} \times$ Female & & & & $.157^{*}$ \\
\hline$\chi^{2}$ & 6,546 & 6,551 & 3,646 & 6,566 \\
\hline$N$ (spells) & 33,468 & 33,468 & 21,194 & 33,468 \\
\hline Pct. completed & .510 & .510 & .462 & .510 \\
\hline
\end{tabular}

${ }^{a}$ Entries are unstandardized regression coefficients from a survival model. Each equation also contains seven dummy terms which depict the effect of duration in grade (see text Eq. 2). In this formulation, the constant term in the covariate vector is not identified and is absorbed into the period terms.

${ }^{b}$ Equation (3) was estimated using only spells in the clerical foci. Terms for SGL11-14 and SGL15-20 are omitted because there are no clerical workers in these grades.

$c$ "White" is the omitted category among the racial terms; "SGL1-3" is the omitted category among the grade level terms. "Clerical" is a dummy variable, coded one for job foci 1-5 and zero otherwise.

$* p=.01, * * p=.05$.

The home office advantage arises, presumably, from the large volume of job vacancies in this one location, from the relative ease of learning about job openings in one's place of work- even before they are posted, and from the lower personal cost of shifting work groups when this does not entail a change of residence.

The positive home office term suggests that this work location is advantageous for advancement in all ranks of the company. Note, in this regard, the negative effect of home office on the termination rate (column 1 of Table 4). These two location effects are linked by a common interpretation: promotion prospects are better in the home office; for this reason, the likelihood of departing the company 
to seek opportunity elsewhere is much lower at this work site- $68 \%$ of the average rate in other cities ( $\exp [-.382])$.

For which categories of employees is the home office setting most beneficial? With regard to line of work, we expect the advancement prospects of clerical workers to be more sensitive to location. Change of work group is an integral feature of career development in the administrative job lines, as corporations seek to enlarge the perspectives of managers and discourage identification with a single organizational unit or work site (Hall, 1976, p. 161; Kanter, 1977, pp. 29-39, 271-272). In some companies, managerial workers are even scheduled for periodic rotation to different locales, much like army officers. As a consequence, administrative employees are unlikely to become "lost" in a local office.

A comparable investment is rarely made in the career development of clerical employees. These workers often have to rely on their own resources when moving to a company job in a different community, sometimes even to learn about vacancies in distant cities. ${ }^{12}$ Thus, the advantages of home office employment should be more consequential for the attainments of clerical workers. Consistent with this argument, we observe in column (2) of Table 5 a significant, positive effect on the promotion rate from the interaction between home office and clerical focus.

Finally, we have postulated an additional home office advantage in the ceiling grades of the clerical foci, since the mobility blockage and attendant need to shift job focus would be most urgent in these clerical ranks. The most direct approach to this issue is to focus on clerical workers; therefore, in column (3), we report a hazard model for this population group which contains an interaction term between home office and the ceiling grades. (Because few clerical employees in grades 6-7 work outside the home office, a single interaction term with grades 4-7 was estimated.) As proposed in hypothesis 4, we find clear evidence of a location effect, with employees in the ceiling grades benefitting most from a headquarters setting.

To summarize, office location influences attainment prospects in ways that are quite substantial. There is evidence of greater opportunity for home office employees; this is seen in the higher promotion rate and lower rate of termination in this work setting. The home office advantage exists even for administrative workers, who are expected to "move around" as part of their career development. However, it is accentuated for clerical workers, who receive less corporate assistance in changing work locale, and it is greatest for clerical workers in the ceiling grades, for whom a change of job focus can be critical to further advancement.

12 According to the personnel rules of the insurance company, vacancies in grades 12-20 are posted corporate-wide; vacancies in lower grades are posted only in offices within commuting distance of the workplace having the job opening. 


\section{IMPLICATIONS FOR WOMEN'S ATTAINMENT}

It is women who are concentrated in the clerical foci of the insurance company and, as a consequence, exposed disproportionately to the ceiling grade barriers. Moreover, because the bulk of employment in local offices involves clerical tasks, women also are overrepresented in small work places. The career handicaps associated with a small office setting — a limited range of salary grades, few job vacancies, a need to change community to pursue occupational advancementtherefore, fall most heavily on female workers.

Considerations of decision making in the family, negotiating the sometimes conflicting needs of husband's and wife's employment, can exacerbate the impact of a woman's vulnerable position in the organizational structure of the firm. There is much evidence that a wife's work career is rarely accorded equality with husband's employment needs (Pleck, 1977; Poloma and Garland, 1971; Finch, 1983, pp. 134-140); as a consequence, family decisions regarding a change of community, when made for career purposes, tend to reflect husband's work requirements more often than wife's (Hoffman and Reed, 1981; Marwell et al., 1979). A central implication of this argument is that a home office setting would be beneficial to the career attainments of women because of their concentration in job lines having low ceiling grades and because of their limited ability to change community.

These expectations are largely borne out. In Table 5, with the introduction of an interaction term between home office and female [column (4)], it becomes evident that the bulk of the initially observed home office advantage [column (1)] accrues to female employees. For men, the home office benefit translates into a promotion rate that is $6 \%$ higher than in a local office; for women, the increase is $24 \%$. A counterpart to this assessment concerns the impact of home office on the termination rate from the firm. To the extent that departures are stimulated by a lack of advancement opportunity, we would expect a gender interaction with location. Indeed, the termination rate for men is $17 \%$ lower in the home office, while the headquarters effect for women is a $35 \%$ decline in departures [calculations from column (3) of Table 4]. In short, because women are more constrained in making geographic changes, they show a greater benefit from working in a large office setting.

Having commented on the particular consequences of residence location for women's career prospects, we turn to a consideration of the summary implications of the foci ceilings for women's attainment. In column (1) of Table 6, we report a model of the effects of gender and race on the promotion rate, net of tenure and the human capital variables. The female disadvantage amounts to a promotion rate that is $84 \%$ of the male value [exp (-.170]. In column (2), dummy terms have been added for salary grade, so that the portion of the promotion disparity which arises from the gender distribution over the corporate ranks is held constant. Inclusion of this control raises the female promotion rate to $90 \%$ of the male value [exp (-.106)] by permitting the low rate of advancement in the ceiling grades to be taken into account as a fact of organizational structure. 
TABLE 6

Gender Effects on the Rate of Promotion, by Salary Grade ${ }^{a}$

\begin{tabular}{|c|c|c|c|}
\hline \multirow[b]{2}{*}{ Variable $^{b}$} & \multicolumn{3}{|c|}{ Model } \\
\hline & (1) & (2) & (3) \\
\hline Black & $-.095^{*}$ & $-.096 *$ & $-.100 *$ \\
\hline Oriental & .009 & .043 & .040 \\
\hline Hispanic & $-.108 *$ & $-.101 *$ & $-.107 *$ \\
\hline Female & $-.170 *$ & $-.106^{*}$ & $-.114^{*}$ \\
\hline Education (years) & $.068^{*}$ & $.061 *$ & $.060 *$ \\
\hline Age (years) & $-.045^{*}$ & $-.044 *$ & $-.043^{*}$ \\
\hline $\mathrm{Age}^{2}$ & $.00025^{*}$ & $.00024 *$ & $.00024 *$ \\
\hline Seniority (mos.) & $-.0029 *$ & $-.0029 *$ & $-.0028 *$ \\
\hline Seniority $^{2}$ & $.0000043^{*}$ & $.0000040 *$ & $.0000036^{*}$ \\
\hline SGL4-5 & & $-.223 *$ & -.068 \\
\hline SGL6-7 & & $-.112 *$ & .001 \\
\hline SGL8-9 & & $.080 * *$ & .002 \\
\hline SGL10-12 & & $.096 * *$ & .047 \\
\hline SGL13-15 & & .034 & -.022 \\
\hline SGL16-20 & & -.035 & -.091 \\
\hline Fem $\times$ SGL4-5 & & & $-.184 *$ \\
\hline Fem $\times$ SGL6-7 & & & $-.182 *$ \\
\hline Fem $\times$ SGL8-9 & & & $.162 *$ \\
\hline Fem $\times$ SGL10-12 & & & $.143^{* *}$ \\
\hline Fem $\times$ SGL13-15 & & & $.279^{*}$ \\
\hline Fem $\times$ SGL16-20 & & & $.474^{*}$ \\
\hline$\chi^{2}$ & 6,159 & 6,338 & 6,407 \\
\hline$N$ (spells) & 33,468 & 33,468 & 33,468 \\
\hline Pct. completed & .510 & .510 & .510 \\
\hline
\end{tabular}

${ }^{a}$ Entries are unstandardized regression coefficients from a survival model. Each equation also contains seven dummy terms which depict the effects of duration periods (see text equation 2). The constant term in the covariate vector is not identified and is absorbed into the period terms.

$b$ "White" is the omitted category among the racial terms; "SGL1-3" is the omitted category among the grade level terms.

$* p=.01, * * p=.05$.

It is instructive to carry the decomposition one step further and examine gender differences in the promotion rate by salary grade level. This analysis is reported in column (3), with the results summarized in column (4) of Table 7. Entries in the latter column convey the female promotion rate as a proportion of the male rate. The middle grades (SGL's 4-7) capture the effects of the foci ceilings. The female disadvantage is greatest here because the majority of men in these ranks are in the initial grades of administrative job lines and, therefore, do not face the promotion blockage. In grades $8-12$, immediately above the clerical ceilings, there is little in the way of a gender disparity (note, incidentally, a similar finding by DiPrete and Soule, 1988). In the senior ranks of the company, in contrast, there is clear evidence of a higher promotion rate for women. 
TABLE 7

Summary of Gender Differences in the Rate of Promotion, by Salary Grade Level

\begin{tabular}{|c|c|c|c|c|}
\hline \multirow[b]{2}{*}{ Variable } & \multirow{2}{*}{$\begin{array}{c}\text { (1) } \\
\text { Percent } \\
\text { female }\end{array}$} & \multicolumn{2}{|c|}{$\begin{array}{l}\text { Regression } \\
\text { coefficient }\end{array}$} & \multirow{2}{*}{$\begin{array}{c}\begin{array}{c}\text { Female } \\
\text { advantage }^{a}\end{array} \\
\begin{array}{c}(4) \\
\exp (\Delta)-1\end{array}\end{array}$} \\
\hline & & $\begin{array}{c}(2)^{b} \\
\text { Male }\end{array}$ & $\begin{array}{c}(3)^{c} \\
\Delta_{(\mathrm{F}-\mathrm{M})}\end{array}$ & \\
\hline Average effect (No SGL controls) ${ }^{d}$ & 72 & 0 & -.170 & .84 \\
\hline Average effect (SGL controls present) ${ }^{e}$ & 72 & 0 & -.106 & .90 \\
\hline \multicolumn{5}{|l|}{ Grade level ${ }^{f}$} \\
\hline SGL1-3 & 91 & 0 & -.114 & .89 \\
\hline SGL4-5 & 88 & -.068 & -.298 & .74 \\
\hline SGL6-7 & 72 & .001 & -.296 & .74 \\
\hline SGL8-9 & 49 & .002 & .048 & 1.05 \\
\hline SGL10-12 & 30 & .047 & .029 & 1.03 \\
\hline SGL13-15 & 17 & -.022 & .165 & 1.18 \\
\hline SGL16-20 & 11 & -.091 & .360 & 1.43 \\
\hline
\end{tabular}

${ }^{a}$ Female promotion rate as a proportion of the male rate.

${ }^{b}$ Zero entry denotes reference category.

${ }^{c}$ Difference between female and male effects.

${ }^{d}$ Entries in columns (2) and (3) are from Table 6, column 1.

${ }^{e}$ Entries in columns (2) and (3) are from Table 6, column 2.

${ }^{f}$ Entries in columns (2) and (3) are from Table 6, column 3.

The summary female disadvantage in rate of advancement-a promotion rate that is $84 \%$ of the male rate [column (1) of Table 6] — therefore, masks a complex pattern of gender disparities over the salary grades. It is difficult to account for the female advantage in the senior ranks, which reaches 1.43 times the male promotion rate. Indeed, this finding is hardly consistent with conventional wisdom about the impediments which women experience in attempting to scale the corporate ladder (e.g., Sokoloff, 1980; Wall Street Journal, 1980; Kanter, 1977). Yet, it does correspond to a somewhat different assessment of the locus of women's career difficulties.

The first aspect of that assessment relates to the now well-documented observation about the intrusion of family responsibilities into women's work lives; in short, to how the competing demands of career and family shape the work commitments women are able to make (Bourne and Wikler, 1978; Hoffman and Reed, 1981; Coverman, 1983; Wilkie, 1988; Spilerman and Schrank, 1991). We suggest that the women most able to avoid the heavy career costs of family obligations are those with the financial resources to "buy out" from a portion of household responsibilities. Women in high corporate ranks are better situated financially to employ a housekeeper or a childcare worker. Also, because of a tradition of marriage hypergamy in American society, it is precisely these women who are likely to have a spouse with commensurate or higher income.

The preceding argument suggests that women in high corporate ranks carry less 
of a burden of household responsibilities than do their counterparts in lower grades. It suggests that if a firm does not discriminate in its advancement decisions, there should be little difference in the promotion rates of men and women, at least in the grades where ceiling barriers are not an issue. Quite possibly, this argument accounts for the negligible gender disparity in grades $8-12$. It does not, however, explain why women in the most senior ranks should have a higher promotion rate than men.

The second aspect of our assessment speaks to this issue. When the results in Table 7 were shown to several managers in the insurance company, they responded by pointing to the governmental pressures for affirmative action. These had been keenly felt during the 1970's - the period to which our data pertainand had motivated corporate programs to increase the representation of women in policy-making positions. Moreover, because the base percentage female in the senior ranks was low (column 1 of Table 7), a policy of facilitating women's advancement could be pursued with little detrimental impact on the promotion opportunities of men and, therefore, with little employee opposition.

Finally, the data on the distribution of women over the salary grades (column 1) permits some insight into the sources of the gender disparity in average rate of advancement. In grades 8-20, women experience no promotion disadvantage; on average, they advance more rapidly than men. Yet, relatively few women reach these ranks; the bulk of female employment remains in lower grades, in the clerical foci, where they butt up against the mobility barriers. Indeed, the central theme underlying women's attainment in this company-and in much of American corporate life-is one of concentration in clerical lines and exposure to ceiling barriers. Few men encounter this blockage because most enter the company directly into the administrative foci.

\section{CONCLUSION}

In this paper, we have distinguished between merit- and vacancy-driven promotion regimes. This distinction permits the personnel rules which underlie attainment to be linked to particular organizational features, such as job ladders and a decentralized firm structure. Merit-driven promotion is a relatively recent institutional development, deriving from the construction of grade level hierarchies and a definition of promotion as advancement within such a hierarchy, rather than among ranked occupations. Since there is no essential association between status and functional task in a grade level formulation, the need for a vacancy in order for promotion to occur is formally eliminated - an employee can be promoted while continuing in the same job-though, for reasons of cost containment, a firm might well choose to ration the allocation of high grade positions.

Organizational structures, such as job ladders with their associated ceiling grades, intrude into this formulation of advancement by introducing barriers to mobility. The barriers may be permeable, reflecting generous transfer provisions 
in a firm, but they nonetheless influence attainment in two ways: a vacancy in an appropriate destination unit must be available, and employees will differ in their ability to take advantage of this move possibility, especially if the transition requires a family dislocation such as a change of residence. In speaking of vacancy-driven promotion, we emphasize that there is no implication that merit is unimportant in the decision to advance an employee, only that a vacancy is vital.

In the context of this formulation, it becomes clear why women are disadvantaged in their career prospects. We have not addressed the question of why women enter the company in the clerical job lines-this would require a different database from the one available to us. However, given entry position, it is evident that women must contend, more frequently than men, with ceiling grade barriers. Moreover, in local offices, women are further disadvantaged in that a change of job ladder can require a residence move, which is especially difficult for working wives to negotiate (Hoffman and Reed, 1981). Our findings that the promotion disadvantage disappears in the senior grades, where ceiling barriers are not in evidence, and that women have higher rates of advancement and lower termination rates in the headquarters setting, where dislocations from a change of corporate unit are modest, bolsters our argument about the differential vulnerability of men and women to particular organizational structures.

A modest reformulation of the promotion categories may be in order. The distinction that we developed derives, in part, from the kinds of job changes that are discernible in the insurance company's data file; however, a somewhat different categorization may prove more productive for theoretical purposes. In particular, we suggest that three kinds of within-firm moves be distinguished: moves along a job ladder (merit-driven promotions in the present paper), moves between job ladders that are frequently undertaken and whose consequences are well understood by the employee, such as shifts in anticipation of a ceiling grade barrier (routine job changes), and moves that are less common in the firm, which offer the prospect of unusual opportunity but carry a risk because of the break in established obligations and expectations between employee and supervisor (strategic moves).

The value of this categorization is that the strategic moves may prove to be a strong predictor of high attainment in a firm. At the same time, it is likely that these moves will be productive only if the timing is correct, if an appropriate track record has been previously established, and if such moves are not undertaken too frequently by an employee. These observations suggest a more general conceptual approach to the analysis of attainment than we have undertaken. They would orient attainment research to a consideration of careers in a firm-sequences of positions-instead of a focus on solitary moves. Fortunately, this generalization can be carried out within the present methodological framework; all that is required is the addition of characteristics of past job changes to an equation explaining either the waiting time to promotion from current grade or status attainment in the firm. 


\section{REFERENCES}

Althauser, R. P., and Kalleberg, A. (1981). "Firms, occupations, and the structure of labor markets: A conceptual analysis," in Sociological Perspectives on Labor Markets (I. Berg, Ed.), pp 119-149, Academic Press, New York.

Baron, J. N., and Bielby, W. T. (1980). "Bringing the firms back in: Stratification, segmentation, and the organization of work," American Sociological Review 45, 737-765.

Baron, J. N., and Bielby, W. T. (1982). "Workers and machines: "Dimensions and determinants of technical relations in the workplace," American Sociological Review 47, 175-188.

Baron, J. N., and Bielby, W. T. (1984). "The organization of work in a segmented economy," American Sociological Review 49, 454-473.

Beck, E. M., Horan, P. M., and Tolbert, C. M., II (1978). "Stratification in a dual economy: A sectoral model of earnings discrimination," American Sociological Review 43, 704-720.

Blau, P., and Duncan, O. D. (1967). The American Occupational Structure,” Wiley, New York.

Blossfeld, H., and Mayer, K. U. (1988). "Labor market segmentation in the federal republic of Germany: An empirical study of segmentation theories from a life course perspective," European Sociological Review 4, 1-17.

Bourne, P., and Wikler, N. J. (1978). "Commitment and the cultural mandate: Women in medicine," Social Problems 25, 430-440.

Bridges, W., and Villemez, W. J. (1994). The Employment Relationship: Causes and Consequences of Modern Personnel Administration, Plenum Press, New York.

Bruderl, J., Diekmann, A., and Preisendorfer, P. (1991). "Patterns of intraorganizational mobility: Tournament models, path dependency, and early promotion effects," Social Science Research 20, 197-216.

Carroll, G. R., and Mayer, K. U. (1986). "Job shift patterns in the Federal Republic of Germany: The effects of social class, industrial sector, and organizational size," American Sociological Review 51, 323-341.

Coverman, S. (1983). "Gender, domestic labor time, and wage inequality," American Sociological Review 48, 623-637.

Daymont, T. (1980). "Pay premiums for economic sector and race: A decomposition," Social Science Research 9, 245-272.

DiPrete, T. A., and Soule, W. T. (1986). "The organization of career lines: Equal employment opportunity and status advancement in a federal bureaurcacy," American Sociological Review 51, 295-309.

DiPrete, T. A., and Soule, W. T. (1988). "Gender and promotion in segmented job ladder systems," American Sociological Review 53, 26-40.

Featherman, D., and Hauser, R. M. (1978). Opportunity and Change, Academic Press, New York.

Finch, J. (1983). Married to the Job: Wives' Incorporation in Men's Work, Allen and Unwin, London, UK.

Flinn, C. J., and Heckman, J. (1983). "Are unemployment and out of the labor force behaviorally distinct labor force states?," Journal of Labor Economy 1, $28-42$.

Freedman, M. K. (1976). Labor Markets: Segments and Shelters, Allanheld, Osmun \& Co., Montclair, NJ.

Grandjean, B. D. (1981). "History and career in a bureaucratic labor market," American Journal of Sociology 86, 1057-1092.

Hall, D. T. (1976). Careers in Organizations, Goodyear Press, Pacific Palisades, CA.

Hoffman, C., and Reed, J. S. (1981). "Sex discrimination?- the XYZ affair," The Public Interest 62, 21-39.

Jencks, C. (1972). Inequality, Basic Books, New York.

Kalbfleisch, J., and Prentice, R. (1980). The Statistical Analysis of Failure Time Data, Wiley, New York.

Kanter, R. M. (1977). Men and Women of the Corporation, Basic Books, New York. 
Marwell, G., Rosenfeld, R., and Spilerman, S. (1979). “Geographic constraints on women's careers in academia," Science 205, 1225-1231.

Medoff, J. L., and Abraham, K. G. (1980). "Experience, performance, and earnings," The Quarterly Review of Economics XCV, 703-736.

Medoff, J. L., and Abraham, K. G. (1981). "Are those paid more really more productive? The case of experience," The Journal of Human Resources 16, 186-216.

Miller, R. G. (1981). Survival Analysis, Wiley, New York.

Mincer, J. (1986). “Wage changes in job change,” Research in Labor Economics 8A, 171-197.

Mobley, W. H. (1982). Employee Turnover: Causes, Consequences, and Control, Addison Wesley, Reading, PA.

Petersen, T., Spilerman, S., and Dahl, S. (1990). "The structure of employment terminations among clerical employees in a large burearucracy," Acta Sociologica 32, 319-338.

Pettman, B. O. (1973). "Some factors influencing labor turnover: A review of research literature," Industrial Relations Journal 4, 43-61.

Pleck, J. H. (1977). “The work-family role system," Social Problems 24, 417-427.

Poloma, M. M., and Garland, N. (1971). "The myth of the egalitarian family: Familial roles and the professionally employed wife," in The Professional Woman (A. Theodore, Ed.), pp. 741-761, Schenkman, Cambridge, MA.

Prendergast, C. (1996). "What happens within firms?" NBER Working Paper No. 5802. National Bureau of Economic Research, Cambridge, [unpublished]

Rosenbaum, J. E. (1984). Career Mobility in a Corporate Hierarchy, Academic Press, New York.

Rosenfeld, R. (1983). “Sex segregation and sectors,” American Sociological Review 48, 637-655.

Sandefur, G. (1981). "Organizational boundaries and upward job shifts,” Social Science Research 10, $67-82$.

Sibson, R. E. (1981). Compensation,Amacom, New York.

Sicherman, N. (1990). "Education and occupational mobility," Economics of Education Review 9, $163-179$.

Sicherman, N., and Galor, O. (1990). "A theory of career mobility," Journal of Political Economy 98, 169-192.

Sofer, C. (1970). Men in Mid-Career: A Study of British Managers and Technical Specialists, Cambridge Univ. Press, Cambridge, UK.

Sokoloff, N. (1980). Between Money and Love, Praeger, New York.

Sorenson, A. B., and Tuma, N. B. (1980). "Labor market structures and job mobility," Research in Social Stratification and Mobility 1, 67-94.

Spilerman, S. (1986). "Organizational rules and the features of work careers," Research in Social Stratification and Mobility 5, 41-102.

Spilerman, S., and Schrank, S. (1991). "Responses to the intrusion of family responsibilities in the workplace," Research in Social Stratification and Mobility 10, 27-61.

Tolbert, C. M. (1982). “Industrial segmentation and men's career mobility,” American Sociological Review 47, 457-477.

Tuma, N. M., Hannan, M., and Groeneveld, L. (1979). "Dynamic analysis of event histories," American Journal of Sociology 84, 820-854.

U.S. Department of Labor. (1970). Seniority in Promotion and Transfer Provisions, Bulletin1425-11, Bureau of Labor Statistics, Government Printing Office, Washington, DC.

Van Maanen, J. (1977). "Experiencing organization: Notes on the meaning of careers and socialization," in Organizational Careers: Some New Perspectives (J. Van Maanen, Ed.), pp. 15-48, Wiley, New York.

Wallace, M. J., and Fay, C. H. (1983). Compensation Theory and Practice, Kent Publishing Company, Boston.

Wall Street Journal. (1980). "Few women get top business jobs despite progress of past decade." July 25, 1980, p. 15.

Wilkie, J. R. (1988). "Marriage, family life, and women's employment," in Women Working, 2nd edition (A. H. Stromberg and S. Harkess, Eds.), pp. 149-166, Mayfield, Mountain View, CA. 